\title{
What Makes Women Social Cynics? An Exploratory Study
}

\author{
Faiz Younas ${ }^{1}$, Nasreen Akhtar ${ }^{2}$, Vicar Solomon ${ }^{3}$
}

\begin{abstract}
Although women are comprised almost half of the human population, still their experiences as a minority within the larger social framework, affect the affective and behavioral aspects of their personality including social cynicism. Unfortunately, social cynicism had never been empirically studied from the perspective of women, especially indigenously. By applying a qualitative approach, this study explored an indigenous understanding of social cynicism in a sample of $(N=20)$ young adult women through a focus group discussion $(n=6)$ and open-ended questionnaires $(n=14)$, respectively. Five central themes emerged after the thematic analysis of the transcribed data that included gender inequality and exploitation, misrepresentation and misinformation, negative beliefs and generalizations, authority and control, and lastly, safety and security concerns. The findings showed several distinctive and indigenous themes like paternal authoritarianism, religion-based misinterpretation and sense of imminent danger while a few sub-themes were consistent with the previous literature. By exploring the construct of social cynicism in women, this study had not only broadened the limits of existing research literature on this construct but its themes could be applied for indigenous theory and scale development.
\end{abstract}

Keywords: Social Cynicism, Women, Gender Inequality, Paternal Control, Safety Concerns

Received: 15 November 2021; Revised Received: 03 December 2021; Accepted: 08 December 2021

${ }^{1}$ Lecturer, Institute of Applied Psychology, University of the Punjab, Lahore, Pakistan. ${ }^{2}$ Assistant Professor, Department of Psychology, Government College University, Lahore, Pakistan.

${ }^{3}$ Assistant Professor, Department of Psychology, University of Jhang, Pakistan.

\section{Corresponding Author Email:}

vicarsolomon5@gmail.com

\section{Introduction}

In a recent global social report, it was found that differential access to resources, power, autonomy, and status exists across various social groups that create a widespread social inequality (United Nations Department of Economic and Social Affairs [UNDESA], 2020). Undoubtedly, this limited accessibility has social and psychological repercussions, especially for the minority groups who may develop a certain degree of mistrust towards the existing social institutions, thus making them socially cynical. Originally derived from ancient Greek philosophy, cynicism refers to communal alienation due to observance of virtuous ideals; however, in modern times, it involves the rejection of ethical values while questioning the concepts of honesty and truth with scepticism (Levent \& Keser, 2016). At times regarded as an attitude (Nair \& Kamalanabhan, 2010), it is also considered a dispositional construct that assesses people and the world in terms of good and bad (Stavrova \& Ehlebracht, 2016).

When explored in a social context, it is called social cynicism, which can be defined as a negative view of human nature that involves a biased view against some groups of people, a mistrust of social institutions, and a disregard of ethical means for achieving ends (Bou et al., 2014). Burgess (2015) argued that people who score high on social cynicism believe that the world is a mean-spirited place where

This article is distributed under the terms of the Creative Commons Attribution Non Commercial 4.0 License (http://www.creativecommons.org/licenses/by-nc/4.0/) which permits non-Commercial use, reproduction and distribution of the work without further permission provided the original work is attributed as specified. 
others cannot be trusted. This could be inferred as a sense of disempowerment that might lead to social cynicism when people were unable to influence their situations and circumstances.

Several studies have investigated social cynicism in organizational settings and generated suitable empirical literature that highlights its dynamics at the workplace. Leung et al. (2010) reported its negative relationship with job satisfaction. Also, social cynic leaders are found to be undermining their followers' motivation and performance (Byza et al., 2017). Similarly, employees' social cynicism appeared to be related to organizational cynicism only when it is conceptualized as cognition instead of an affect or behavior (Kwantes \& Bond, 2019). Moreover, in an indigenous study, Ahmad et al. (2021) discovered a direct and positive effect of social cynicism on perceived bullying in the workplace. Similarly, Indibara and Varshney (2020) found that negative affectivity moderated the influence of social cynicism on negative inferred motives thus highlighting cynicism in consumers.

As a disposition, studies have also highlighted its psychological effects on individuals. A study concluded social cynicism to be associated with negative affect (Lau et al., 2021) while reporting that cynicism negatively predicts well-being (Bakioğlu \& Kiraz, 2019). Also, Choy et al. (2021) reported that individuals with a higher level of social cynicism would not show much empathy as a result of social exclusion. Moreover, individuals with high social cynicism reported higher suicidal behavior (Dangel et al., 2018).

In the context of the COVID-19 pandemic, it was found that the health belief model and generalized social beliefs of social cynicism can be applied for a better understanding of adherence and promotion of precautions against COVID-19 (Tong et al. 2020). Similarly, Kumar et al. (2021) reported a negative relationship of social cynicism with COVID-19 related precautionary measures like physical distancing, hand washing and avoiding touching the face.

Further, it was found to be negatively related to perceived self-efficacy (Chan \& Tam, 2021) while also having a positive relationship with moral disengagement (Alexandra, 2019) and positively predicted gambling propensity (Wu et al., 2019) and self-effacement (Chen et al, 2017). David and Bernardo (2021) reported that it negatively influenced students' perceived academic control. A study further argued that it negatively affect attitudes towards codes of ethics as well as religiosity in students (Putranta, 2020) while another concluded that higher levels of social cynicism predicted lower levels of school belonging in university students (Li et al., 2020). Moule et al. (2019) reported that cynicism increased the belief that police is too militarized.

It is significant to note that the minority group members showed higher cynicism than the majority Caucasian, white population (Fetchenhauer \& Dunning, 2010). Similarly, Leung et al. (2012) also found that male dominance increased social cynicism in women, though men reported higher social cynicism than women. Also, it's worth mentioning that both of these studies were concerned with the intensity of the social cynicism across race or gender rather than observing the nature of the phenomenon itself across the said demography. Therefore, it can be argued that women's experience of social cynicism might be different, rather unique from men. Arguably, research is clear on the fact that in any patriarchal society, power, control, decision-making, and authority are occupied mainly by men where they receive more prestige, influence, and wealth than women (Helgesen, 2020). These powerbased aspects would lead to a wide range of gender-based discrimination that women experience in their personal and professional lives regularly. As in a crosscultural study, Alexandra et al. (2017) found that social cynicism at the individual 
level has a positive relationship with social dominance orientation. This suggests that in a patriarchal man-dominating society, men are socially predisposed to project and assert social dominance.

These pieces of evidence established that even though women comprised almost half of the human population, their subordinate position in the patriarchal society makes them more vulnerable to psychological harms, even reported to develop social cynicism, therefore, it would be essential to understand this construct from the subjective point of view of women as Schwartz and Rubel (2005) also pointed out gender dynamics and configurations vary from culture to culture. These findings highlighted how pertinent it would be to investigate social cynicism from an indigenous point of view, owning to unique cultural practices, social norms and religious context.

\section{The Objective of the Study}

The objective of the current study was to develop an understanding of the experiences of young Pakistani adult women regarding social cynicism and to highlight the social situations and institutions responsible for their experiences of social cynicism.

\section{Research Question}

What is the perspective of women on the contributing social situations and institutions responsible for their experiences of social cynicism?

\section{The Rationale of the Study}

Even though women are almost numerically equal to men, their experiences of discrimination in a patriarchal society seemed to delegate them a unique subordinate and minority position, affecting their psychological health and well-being. Although, scant available literature showed that male dominance could lead to social cynicism in women (Leung et al. 2012), but an indigenous, culturally relevant empirical explanation was missing that could have explored the nature of this construct instead of just its intensity or prevalence across demographics. Inferring from the research scholarship (Helgeson, 2020), it is evident that gender is configured differently in different cultures. This can be another reason to understand social cynicism in women, indigenously.

This highlighted that an in-depth exploration of social cynicism in women is unavailable. That's where the present study could be justified as it aimed to fill the existing research gap and would provide an exclusive exploration of a psychological construct, which would probe into the unique cultural and indigenous dynamics of social cynicism.

\section{Method \\ Sampling}

By applying a qualitative research approach, a sample of $(N=20)$ young adult women were recruited in two stages through a non-probability convenient sampling technique from a public sector university. In the first stage, data was collected through a focus group discussion (FGD) with $(n=6)$ young adult women while in the second stage, an open-ended questionnaire was administered to $(n=14)$ young adult women.

Only young adult women studying in a leading public sector university of Lahore were recruited, who had previous experience of participating in research projects, with an age range of (20-23) years with $(M=21.1, S D=.94)$, without any visible or reported physical or mental health issue. All of the participants had been studying at the university for at least two years, while most of them were middle born and belonged to the nuclear family system with above-average monthly family income. 
Table 1

Sociodemographic Characteristics of Participants $(N=20)$

\begin{tabular}{|l|l|l|l|l|}
\hline Variables & $\boldsymbol{n}$ & $\boldsymbol{\%}$ & $\boldsymbol{M}$ & $\boldsymbol{S D}$ \\
\hline Age & & & 21.1 & .94 \\
\hline 20 & 6 & 30 & & \\
\hline 21 & 8 & 40 & & \\
\hline 22 & 4 & 20 & & \\
\hline 23 & 2 & 10 & & \\
\hline Educational Experience (in years) & & & 14.3 & .46 \\
\hline 14 & 14 & 70 & & \\
\hline 15 & 6 & 30 & & \\
\hline Monthly Family Income (in PKR) & & & 136,000 & 95205.04 \\
\hline $0-100,000$ & 14 & 70 & & \\
\hline $100,001-200,000$ & 2 & 10 & & \\
\hline $200,001-300,000$ & 3 & 15 & & \\
\hline $300,001-400,000$ & 1 & 5 & & \\
\hline Family System & & & & \\
\hline Joint & 3 & 15 & & \\
\hline Nuclear & 17 & 85 & & \\
\hline Birth Order & & & & \\
\hline First born & 4 & 20 & & \\
\hline Middle born & 13 & 65 & & \\
\hline Last born & 3 & 15 & & \\
\hline
\end{tabular}

\section{FGD and Questions Schedule}

All FGD and open-ended questionnaire participants were first asked to provide basic sociodemographic information including age, birth order, education level, family system and monthly family income. Then, the following questionnaire schedule was followed to inquire about social cynicism:

1) How do you think women experience social cynicism?

2) What kind of social situations can lead to the experiences of social cynicism?

3) How can social institutions play a role in developing social cynicism?

4) How does social cynicism affect you at a personal level?

\section{Procedure}

First of all, permission to conduct this study was taken from the Department of Psychology Ethical Committee, Government College University, Lahore, Pakistan. Initially, a definition of social cynicism by Burgess (2015) was selected and later shared with the participants, while after reviewing the available literature on the construct, a questionnaire schedule was finalized in consultation with experts of the field. The data collection process involved two stages.

In stage one, an FGD was conducted via Zoom with $(n=6)$ young adult women. Observing all the ethical considerations, they were briefed about the nature and purpose of the FGD, while explicit permission was taken to audio record the conversation and was assured of the fact that it would only be used for academic and research purposes, anonymously. FGD lasted for 130 minutes in which the definition of social cynicism by Burgess (2015) was presented followed by a question schedule that explored social cynicism.

In the second stage, 18 participants were contacted online to fill an open-ended questionnaire that comprised of Burgess (2015) definition of social cynicism with the same question's schedule used in FGD 
but open-ended format along with a consent form and sociodemographic information sheet. A total of $(n=14)$ young adult women responded and sent back filled forms. All ethical protocols were strictly followed during the whole process. For maintaining further confidentiality, all participants were assigned a random identity code (SC-01 to SC-20), that would further be used while sharing their respective illustrative quotations. In the end, all the participants were thanked for their participation and cooperation. The audio recording of the FGD was then transcribed and translated, while data from open-ended questionnaires were merged with it and by using thematic analysis technique, themes were generated.

\section{Results and Discussion}

Following Braun and Clarke (2006) guidelines, an inductive thematic analysis approach was used to analyze the whole data. All transcriptions and open-ended responses were read several times for better familiarization and understanding. Initially, similar themes were clustered together and further inspected for repetitive themes. The reduced data was further analyzed to generate codes that led to the extraction of central themes with relevant sub-themes. 
Table 2

Central and Sub Themes of FGD on Social Cynicism in Women $(N=20)$

\begin{tabular}{|c|c|c|}
\hline Central Themes & Sub Themes & Example Quote \\
\hline \multirow[t]{5}{*}{$\begin{array}{l}\text { Gender Inequality and } \\
\text { Exploitation }\end{array}$} & Familial discrimination & $\begin{array}{l}\text { "There's no fair play in parental treatment. I can't even go to } \\
\text { my best friend's house or market without taking permission } \\
\text { but my brother is free to do whatever he wants and go } \\
\text { wherever he wants. It's like being a man gives you license to } \\
\text { do everything you desire, without restrictions." (SC-01) }\end{array}$ \\
\hline & Legal discrimination & $\begin{array}{l}\text { "It's hard to get legal justice in Pakistan, especially if you } \\
\text { are a woman. Rather, if you are a minority of any kind, it's } \\
\text { almost impossible to get justice in this country. People will } \\
\text { always find faults in you, no matter how much caution and } \\
\text { care you take. And you will be blamed in the end for every } \\
\text { bad thing." (SC-06) }\end{array}$ \\
\hline & Socio-political discrimination & $\begin{array}{l}\text { "You cannot expect women to be good drivers when all their } \\
\text { lives they are taught to sit back and being chaperoned and } \\
\text { driven to place. This is what invisible discrimination looks } \\
\text { like." (SC-01) }\end{array}$ \\
\hline & Vulnerability to exploitation & $\begin{array}{l}\text { "...even when caesarian isn't needed, doctors will force } \\
\text { women to undergo the surgery just to make money. And of } \\
\text { course, at that point, you can't argue with them or move } \\
\text { around from one hospital to another." (SC-05) }\end{array}$ \\
\hline & Misrepresentation in media & $\begin{array}{l}\text { "Pakistani dramas are the worst. You will find a cheating } \\
\text { husband or a female lead's sister romantically involved with } \\
\text { her brother in law in every other play. What kind of message } \\
\text { these dramas are giving to the audiences other than creating } \\
\text { mistrust? Then, women are mostly depicted extremely } \\
\text { negative while men are shown as either naïve or saviors of } \\
\text { women." (SC-02) }\end{array}$ \\
\hline
\end{tabular}

(Table Continued) 
Social misrepresentation

Religion-based misinterpretation

Negative Beliefs and

Generalizations
Negative parental expectations

Negative generalizations through media
"You must have heard that [aurat he aurat ke dushman hai] a woman is the real enemy of one other. Such kind of social commentary puts all the blame on women, leaving men completely out of this discussion as if they are the victims." (SC-04)

"Islam has given us many rights but all that we hear from (moulvis) mullahs is baseless religion-based discrimination in which women are presented as a temptation that needs to be hidden or covered. Men are related as in charge of women who can decide whatever they feel like about women's lives who need to obey and follow them otherwise there will be consequences in this world and hereafter." (SC03)

"Although my parents are educated, they still hold beliefs like [kisi ke buri nazar lag jaye ge] someone's evil eye can lead to personal problems, therefore, one should never share their positive life events or achievements with others because you never know who will cast an evil eye on you and then everything will be destroyed." (SC-04)

"Whenever I open my Instagram, mostly my timeline shows stories of women who reporting personal incidents of abuse and violence, or there's always someone threatening or bullying them. Though I don't want to undermine or disregard their experiences but it's like the bombardment of negative experiences happening to everyone all over social media that I believe isn't the only thing happening in this world. I think people do generalize such experiences or at times, exploit such things to get more attention and followers on social media." (SC-02) 


\section{Central Themes}

Negative future expectation

Authority and Control

Paternal authoritarianism

Control through agents of socialization

Safety and Security Concerns
Parental concern for safety

Sense of imminent danger

\section{Example Quote}

"Honestly, looking at the state of affairs in which we are currently living, I don't have much hope regarding any betterment. Look at the statistics of violence against women and the rise of extremism which is a threat for every sensible and thinking person. I feel it's useless to even fight back against social problems because no matter how much progressive or empowered women we may become, in the end, we have to get married to these problematic and sexist men because there's no other option or choice." (SC-06) "My father believed that becoming a doctor is a respectable and valuable profession for women, so he forced me to opt for pre-medical instead of Fine Arts that I wanted to peruse." (SC-03)

"My father regularly watches Crime Patrol (crime show) and talks about [halaat baray kharab hain] the alarming state of affairs in general. But especially brings it up whenever I have to go outside (out of home) for shopping or to meet friends." (SC-01)

"Travelling alone has become an issue since I have moved to this city for my education. Once I was travelling back to the hostel and I received a call from my father. When he realized I was travelling alone in Uber, he reprimanded me quoting bad incidents. Since that day, I have always been anxious about commuting alone." (SC-05)

"Whenever I go out in a public space, I always have to stay alert and aware of my surroundings because you never know when someone can pinch or harass you. It's like I am in a constant state of threat and this is quite common with women. Just thinking about our safety and anticipating that something bad can happen is itself an emotionally draining experience." (SC-04) 


\section{Figure 1}

Graphical Representation of Themes of Social Cynicism in Women
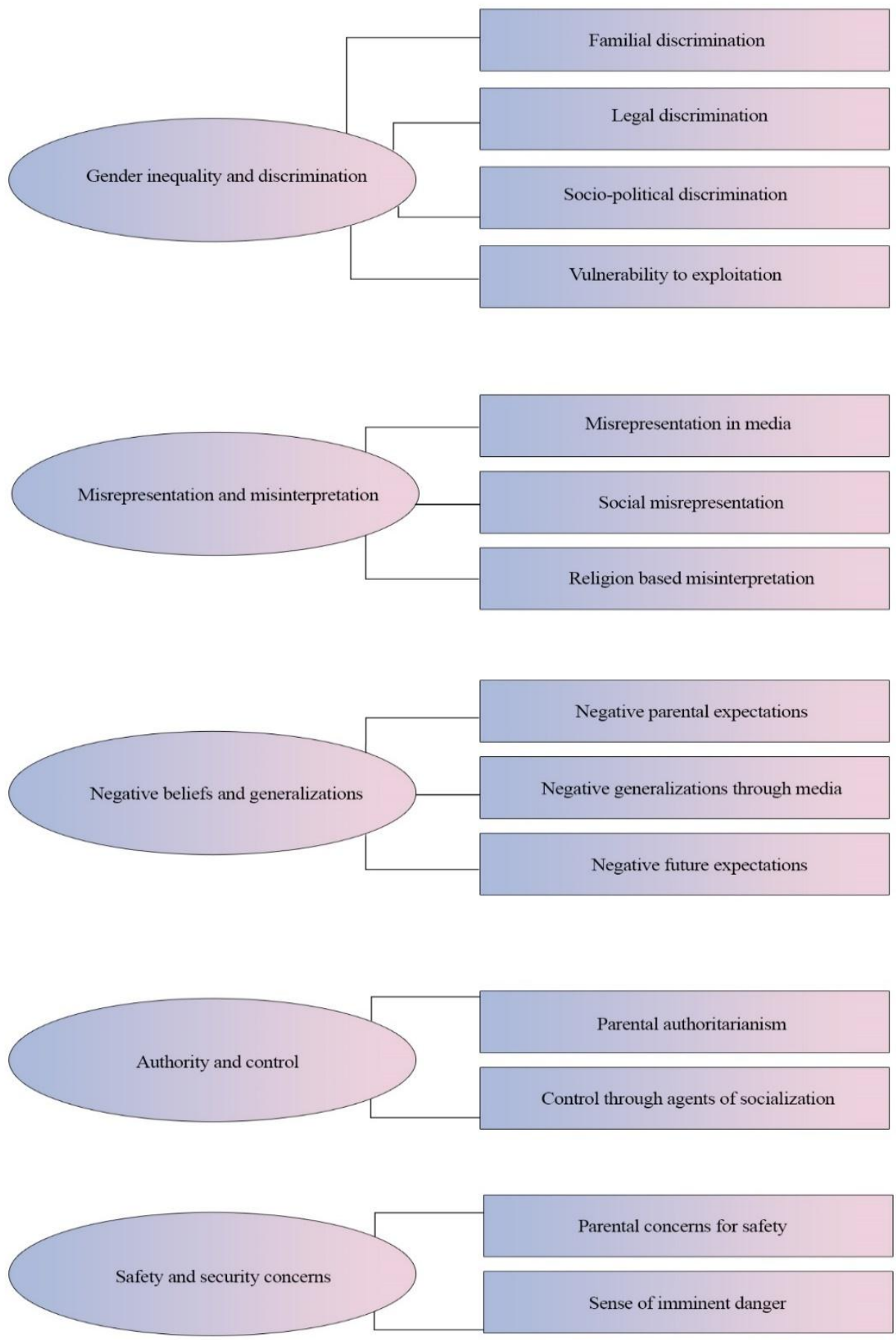

Most of the participants responded in a mixture of both Urdu and English languages for the FGD, therefore, with the help of two bilingual experts, the whole manuscript was translated into English for language consistency. Also, the indigenous and contextual phrases or expressions from the quotations were retained though their English translation was provided for better understanding and comprehension of the manuscript.

Various central and sub-themes were generated from the coding of data that was thoroughly analyzed and eventually 
reduced into five central themes including gender inequality and exploitation, misrepresentation and misinformation, negative beliefs and generalizations, authority and control, and lastly, safety and security concerns.

\section{Gender Inequality and Exploitation}

Gender inequality and exploitation appeared to be the foremost central theme that emerged from the thematic analysis of the FGD conducted to investigate social cynicism in women, as all of the participants talked about gender-based inequality and discrimination at a familial, legal, and socio-political level while also reporting women's vulnerability to exploitation. Addressing familial discrimination, the participant (SC-01) stated:

"There's no fair play in parental treatment. I can't even go to my best friend's house or market without taking permission but my brother is free to do whatever he wants and go wherever he wants. It's like being a man gives you license to do everything you desire, without restrictions".

Further arguing over this sub-theme, the participant (SC-03) reported that families hardly think about investing financially in their sons' education but think a lot when they have to invest in the education of their daughters. To her, it seemed like a costbenefit analysis, where parents assumed educating their sons would be beneficial for their own as they would be financially supporting them, unlike their daughters who would be married off eventually. Similarly, the participant (SC-19) brought in an interesting observation and shared that even the quantity and quality of meal distribution at home is unequal where large pieces of meat were reserved for the men of the house only.

While discussing legal discrimination that women face in society, the participant (SC06) stated:

"It's hard to get legal justice in Pakistan, especially if you are a woman. Rather, if you are a minority of any kind, it's almost impossible to get justice in this country. People will always find faults in you, no matter how much caution and care you take. And you will be blamed in the end for every bad thing."

Similarly, the participant (SC-15) and (SC17) reported a lack of legal justice and action taken against women's complaints of harassment and abuse, with an insensitive attitude of police personnel. They further maintained that the burden of evidence was always on women to prove they had been harassed.

Moving on with this central theme of gender inequality and discrimination, participants also shared their thoughts on socio-political discrimination that women go through in their day to day life. The participant (SC-04) argued that at a societal level it's always a man's word that is considered authentic and valid against a woman. She believed that it's hard to fight back because the system doesn't support women. Further, shedding light on this subtheme, the participant (SC-06) reported:

"Other than having limited political awareness, there are few constituencies where women were restricted to cast a vote in last elections. If they aren't even allowed to cast their vote, which by the way, was in full view of media and government who failed to take any action, how come a woman can think of participating in politics which has been historically a maledominated system, at least that's what I have seen."

Also, the participant (SC-20) reported the availability of limited educational opportunities for women, especially in rural areas where the role of women was restricted to perform domestic chores. Moreover, the participant (SC-01) also shared a rather interesting observation from our day to day life and stated:

"You cannot expect women to be good drivers when all their lives they are taught to sit back and being chaperoned and driven to place. This is what invisible discrimination looks like." 
The last sub-themes explored the potential vulnerability for exploitation of women due to the presence of gender inequality and discrimination in society. It was supported by a participant (SC-06) who claimed that there is a certain social hierarchy where the powerful and privileged individuals could easily exploit and manipulate everyone who is inferior to them, including women, transgender, poor, uneducated and other disadvantaged individuals and communities. Also, the participant (SC-17) reported job-related scams that aimed to exploit women. Moreover, the participant (SC-05) while exploring this sub-theme from the point of view of the health sector argued:

"...even when caesarian isn't needed, doctors will force women to undergo the surgery just to make money. And of course, at that point, you can't argue with them or move around from one hospital to another."

Keeping in mind the research evidence arguing that in any patriarchal system, men held the authority, power and control (Helgeson, 2020), causing gender discrimination (Bukhari \& Ramzan, 2013); in the present study, women also reported experiences of gender inequality and discrimination, either involving their own lives or the lives of other women they have observed in their lives. While Leung et al. (2012), argued that gender discrimination could lead to mistrust and social cynicism and also reported that male dominance can lead to higher social cynicism in women; there is relatively scant indigenous literature supporting the fact that genderbased inequality and injustice could lead to social cynicism in women, although the findings of the present study showed that it was undoubtedly a plausible reason.

\section{Misrepresentation \\ Misinterpretation}

and

The second central theme that emerged from this analysis was misrepresentation and misinterpretation that women reported in the FGD and it was further divided into three sub-themes namely misrepresentation in media, social misrepresentation and religion-based misinterpretation. Talking about the misrepresentation of women in media, the participant (SC-02) shared:

"Pakistani dramas are the worst. You will find a cheating husband or a female lead's sister romantically involved with her brother in law in every other play. What kind of message these dramas are giving to the audiences other than creating mistrust? Then, women are mostly depicted extremely negative while men are shown as either naïve or saviors of women."

Moreover, addressing the social misrepresentation of women, the participant (SC-05) argued owning to her challenging circumstances, women resort to crying but even that is considered as manipulative and devious act just to gain social and public sympathy. Also, the participant (SC-20) reported that society generally regards empowerment in women as a negative trait as it seemed to challenge the patriarchal notions of a dependent and weak woman. Exploration this sub-theme further, the participant (SC-04) reported:

"You must have heard that [aurat he aurat ke dushman hai] a woman is the real enemy of one other. Such kind of social commentary puts all the blame on women, leaving men completely out of this discussion as if they are the victims."

Finally, commenting on the religion-based misinterpretation that can also serve as a reason behind social cynicism in women, the participant (SC-03) reported:

"Islam has given us many rights but all that we hear from (moulvis) mullahs is baseless religion-based discrimination in which women are presented as a temptation that needs to be hidden or covered. Men are related as in charge of women who can decide whatever they feel like about women's lives who need to obey and follow them otherwise there will be consequences in this world and hereafter."

Similarly, the participant (SC-01) while sharing her personal experience reported that whenever her maternal uncles are 
supposed to visit, she had to wear (Shalwar Kameez) because they believed that good Muslim women shouldn't wear western clothes as it's against the teachings of Islam.

Although the studies on the portrayal of women in media had mainly focused on the objectification of women (Huda \& Ali, 2015), while a few others explored the sexualization and misrepresentation of women (Davis, 2018), there wasn't much literature that could connect this misrepresentation to social cynicism in women. The findings of the current study reported the misrepresentation of women in media as well as at a socio-cultural level with gender as a salient feature as a potential cause for social cynicism. Further addressing the subtheme of religion-based misinterpretation reported in the present study, it's quite clear from the scholarship of Muslim feminist scholar Barlas (2019) who claimed that religious texts were misinterpreted and manipulated over the centuries to oppress women. She argued that both men and women are equal in front of Allah. These findings though support this sub-theme, but failed to connect it with social cynicism empirically, which this study purported to do.

\section{Negative Beliefs and Generalizations}

The third central theme regarding social cynicism in women was negative beliefs and generalizations that included three subthemes including negative parental expectations, negative generalizations through media and negative future expectations. While talking about negative parental expectations, a participant (SC-01) mentioned her father who regard everyone as a corrupt person (sub chor hain yahan), and therefore no one should be trusted. Similarly, the participant (SC-04) argued: "Although my parents are educated they still hold beliefs like [kisi ke buri nazar lag jaye ge] someone's evil eye can lead to personal problems, therefore, one should never share their positive life events or achievements with others because you never know who will cast an evil eye on you and then everything will be destroyed."

Similarly, both participants (SC-10 and SC11) reported that they were socialized by their families never to trust others, especially men or those people who might appear to be nice but had some maleficent intentions.

Moreover, sharing her thoughts on the negative generalizations through media, the participant (SC-02) reported:

"Whenever I open my Instagram, mostly my timeline shows stories of women who reporting personal incidents of abuse and violence, or there's always someone threatening or bullying them. Though I don't want to undermine or disregard their experiences, it's like a bombardment of negative experiences happening to everyone all over social media that I believe isn't the only thing happening in this world. I think people do generalize such experiences or at times, exploit such things to get more attention and followers on social media."

Lastly, talking about negative future expectations, the participant (SC-06) argued:

"Honestly, looking at the state of affairs in which we are currently living, I don't have much hope regarding any betterment. Look at the statistics of violence against women and the rise of extremism which is a threat for every sensible and thinking person. I feel it's useless to even fight back against social problems because no matter how progressive or empowered women we may become, in the end, we have to get married to these problematic and sexist men because there's no other option or choice." Similar thoughts were shared by the participant (SC-19) who believed that the current social climate of overwhelming injustice and violence towards women could only leave them hopeless.

Though the findings of the third central theme and its related sub-themes could be related to general research scholarship exploring feeling hopelessness regarding the future (O'Connor et al., 2004), the 
literature seemed extant that could relate negative beliefs and generalizations to social cynicism like the findings of the present study.

\section{Authority and Control}

The fourth emerged central theme was authority and control that was further divided into two sub-themes of parental authoritarianism and control through various agents of socialization. Commenting on parental authoritarianism, the participant (SC-05) shared that her father expected everyone to follow his decisions. It made her feel as if she's a robot who just had to follow commands. Similarly, the participant (SC-01) also shared that she had to seek the permission of his father every time she had to go somewhere and she had to lie to him once when she went for a protest against the motorway rape incident because he wouldn't have allowed her to attend it. She further reported that even her father forced all of her siblings to vote for PTI (Pakistan Tehreek-e-Insaaf) in the last elections.

Moreover, the participant (SC-03) reported: "My father believed that becoming a doctor is a respectable and valuable profession for women, so he forced me to opt for premedical instead of Fine Arts that I wanted to peruse."

Also, while talking about control through agents of socialization, the participant (SC06) pointed out that religion is mostly invoked to control or reprimand women by their families as well as by the society at large. Similarly, the participant (SC-01) shared:

"My father regularly watches Crime Patrol (crime show) and talks about [halaat baray kharab hain] the alarming state of affairs in general. But especially brings it up whenever I have to go outside (out of home) for shopping or to meet friends."

Just like most of the findings of the present study, the themes involving authority and control through parents (Shek, 2007) and other agents of socialization appeared in the literature regarding children and adolescents, but once again the association between these concepts and social cynicism wasn't studied previously.

\section{Safety and Security Concerns}

Fifth and the last central theme that emerged from the analysis of data regarding the social cynicism in women was safety and security concerns that were further divided into parental concerns for safety and a sense of imminent danger. Sharing how the concerns of her parents have affected her, the participant (SC-05) reported:

"Travelling alone has become an issue since I have moved to this city for my education. Once I was travelling back to the hostel and I received a call from my father. When he realized I was travelling alone in Uber, he reprimanded me quoting bad incidents. Since that day, I have always been anxious about commuting alone."

Moreover, sharing her thoughts about a sense of imminent danger that she experienced, the participant (SC-04) reported:

"Whenever I go out in a public space, I always have to stay alert and aware of my surroundings because you never know when someone can pinch or harass you. It's like I am in a constant state of threat and this is quite common with women. Just thinking about our safety and anticipating that something bad can happen is itself an emotionally draining experience."

Similarly, the participant (SC-08) while addressing the pervasive concern for personal safety against potential harassment and abuse in public spaces reported that she would prefer to work as a home-based freelancer rather than daily commuting to a workplace. Also, the participant (SC-09) further argued that such pertinent concerns for safety and security had made women paranoid.

It's evident from the previous literature that the safety and security of women have been of concern as Stark and Meschik (2018) explored the safety of women while using public transportation. Similar findings also 
emerged as a central theme in the current study. Though there is a lack of literature on the association between safety concerns and the development of social cynicism in women, this study can be regarded as a step forward in this direction of the investigation.

\section{Limitations and Suggestions}

The sample comprised of young, university-educated women from both rural and urban backgrounds of Punjab, and therefore, findings cannot be generalized. The emerged themes and sub-themes are indigenous which might be irrelevant to other cultures. It is suggested that the factors which emerged qualitatively must also be explored quantitatively in future studies by potentially undertaking a more comprehensive and diverse sample. This might also enhance the external validity of the themes and subthemes generated in the present study. Through cross-cultural studies, the scope and applicability of present findings can also be tested in future research endeavors.

\section{Conclusions}

It can be concluded from the findings of the present study that gender inequality and exploitation, misrepresentation and misinterpretation, negative beliefs and generalizations, authority and control as well as safety and security concerns appeared to play a significant role in the developing social cynicism in Pakistani women. Keeping in mind the overlapping involvement of family and other social institutions in the development of social cynicism and gender inequality, both government and non-governmental organizations need to develop and implement such policies that can educate and implement awareness plans regarding gender-related issues at a group or institutional as well as the individual family level to address social cynicism.

\section{Implications of the Study}

The present study served as a stepping stone towards a more specific and indigenous understanding of social cynicism in women as the previously available literature hardly explored this phenomenon with women. Therefore, by adding up to the already existing body of scholarship involving this construct, this study would set grounds for the development of indigenous theoretical framework as well as construction and validation of specific assessment tools to investigate and measure social cynicism.

It would also help practicing psychologists and counsellors to better understand their clients if social cynicism appeared to be a contributing factor towards their problems. This would enable them to apply more specific and relevant intervention strategies that might be more effective in addressing their client's issues.

As family and related social institutions emerged to be an overarching reason for gender inequality and social cynicism in women, the government and nongovernmental organizations (NGOs) could plan to develop such policies that might address gender-based inequality at a professional and public level. Further, by involving families and parents in education and awareness programs around gender sensitization and issues, changes could also be brought in at a familial and personal level.

\section{Conflict of Interest}

The authors declare no conflict of interest.

\section{Source of Funding}

The authors declare no funding.

\section{References}

Ahmad, S., Islam, T., \& Kaleem, A. (2021). Workplace Bullying in Pakistan: Mapping the Implications of Social Cynicism and the Moderation of Islamic Work Ethic. In Asian Perspectives on Workplace Bullying and Harassment (pp. 93113). Springer.

Alexandra, V. (2019). The role of social worldviews and self-control in moral disengagement. Personality and Individual Differences, 143, 
74-79.

https://doi.org/10.1016/j.paid.2019. 02.012

Alexandra, V., Torres, M. M., Kovbasyuk, O., Addo, T. B., \& Ferreira, M. C. (2017). The relationship between social cynicism belief, social dominance orientation, and the perception of unethical behavior: A cross-cultural examination in Russia, Portugal, and the United States. Journal of Business Ethics, 146(3), 545-562. https://link.springer.com/article/10. 1007\%2Fs10551-015-2925-5

Bakioğlu, F., \& Kiraz, Z. (2019). Burnout and wellbeing of teacher candidates: The mediator role of cynicism. Anales de Psicología / Annals of Psychology, 35(3), 521528.

https://doi.org/10.6018/analesps.35 .3.354441

Barlas, A. (2019). Believing women in Islam: Unreading patriarchal interpretations of Qur'an. Saqi Books.

Bou Malham, P., \& Saucier, G. (2014). Measurement invariance of social axioms in 23 countries. Journal of Cross-Cultural Psychology, 45(7), 1046-1060.

https://doi.org/10.1177/002202211 4534771

Braun, V., \& Clarke, V. (2006). Using thematic analysis in psychology. Qualitative Research in Psychology, 3(2), 77-101.

Bukhari, F. Y., \& Ramzan, M. (2013). Gender Discrimination: A myth or truth Women status in Pakistan. IOSR Journal of Business and Management, 8(2), 88-97.

Burgess, S. (2015, September 21). The Corrosive Effects of Social Cynicism. Nelson Mandela Metropolitan University Business School. http://businessschool.mandela.ac.za /article/the-corrosive-effects-ofsocial-cynicism

Byza, O. A., Schuh, S. C., Dörr, S. L., Spörrle, M., \& Maier, G. W. (2017). Are two cynics better than one? Toward understanding effects of leader-follower (in-) congruence in social cynicism. Journal of Organizational Behavior,38(8), 1246-1259.

https://doi.org/10.1002/job.2200

Chan, H. W., \& Tam, K. P. (2021). Do people's assumptions about the social world matter? The effects of social axioms on environmental attitude and efficacy beliefs. Journal of Environmental Psychology, 75, 101598. https://doi.org/10.1016/j.jenvp.202 1.101598

Chen, S. X., Ng, J. C., Buchtel, E. E., Guan, Y., Deng, H., \& Bond, M. H. (2017). The added value of world views over self-views: Predicting modest behaviour in Eastern and Western cultures. British Journal of Social Psychology, 56(4), 723-749. https://doi.org/10.1111/bjso.12196

Choy, B. K., Eom, K., \& Li, N. P. (2021). Too cynical to reconnect: Cynicism moderates the effect of social exclusion on prosociality through empathy. Personality and Individual Differences, 178(2), 110871.

http://dx.doi.org/10.1016/j.paid.20 21.110871

Dangel, T. J., Webb, J. R., \& Hirsch, J. K. (2018). Forgiveness and suicidal behaviour: Cynicism and psychache as serial mediators. The Journal of Psychology, 152(2), 77-95. https://doi.org/10.1080/00223980.2 017.1408555

David, A. P., \& Bernardo, A. B. (2021). Social axioms and domain-specific perceived academic control: a study of Filipino students. The Educational and Developmental Psychologist, 38(1), 36-46. 
https://doi.org/10.1080/20590776.2 020.1834832

Davis, S. E. (2018). Objectification, sexualization, and misrepresentation: Social media and the college experience. Social Media and Society. https://doi.org/10.1177/205630511 8786727

Fetchenhauer, D., \& Dunning, D. (2010). Why so cynical? Asymmetric feedback underlies misguided scepticism regarding the trustworthiness of others. Psychological Science, 21, 189$193 . \quad$ http://dx.doi.org/ 10.1177/0956797609358586

Helgeson, V. S. (2020). Psychology of Gender. Routledge.

Huda, A. R. U., \& Ali, R. A. (2015). Portrayal of women in Pakistani media. International Journal of Academic Research and Reflection, 3(1), 12-18.

Indibara, I., \& Varshney, S. (2020). Cynical consumer: how social cynicism impacts consumer attitude. Journal of Consumer Marketing. http://dx.doi.org/10.1108/JCM-072019-3305

Kumar, A., Praveena, P. K., \& Barik, R. R. (2021). Adherence to COVID-19 appropriate behaviour among small scale workers in the unorganized sector in Rajasthan by applying health belief model and generalized social beliefs. International Journal of Community Medicine and Public Health, 8(6), 2805-2811. http://dx.doi.org/10.18203/23946040.ijcmph20211936

Kwantes, C. T., \& Bond, M. H. (2019). Organizational justice and autonomy as moderators of the relationship between social and organizational cynicism. Personality and Individual Differences, 151(1), 109391. https://doi.org/10.1016/j.paid.2019. 04.046

Lau, E. Y. Y., Li, C., Hui, C. H., Cheung, S. F., Lam, J., \& Cheung, S. H. (2021). A longitudinal investigation of the bidirectional relationship of sleep quality with emotional stability and social cynicism in a large community sample. Sleep Health. 7(3), 384-389. https://doi.org/10.1016/j.sleh.2021. 03.007

Leung, K., Ip, O. K., \& Leung, K. K. (2010). Social cynicism and job satisfaction: A longitudinal analysis. Applied

Psychology, 59(2), 318-338. https://doi.org/10.1111/j.14640597.2009.00392.x

Leung, K., Li, F., \& Zhou, F. (2012). Sex differences in social cynicism across societies: The role of men's higher competitiveness and male dominance. Journal of CrossCultural Psychology, 43(7), 11521166. http://doi.org/10.1177/0022022111 422259

Levent, F. \& Keser, S. (2016). Examining the organizational cynicism among teachers at schools: A mixedmethods study. Educational Research and Reviews 11, 20092020.

http://dx.doi.org/10.5897/ERR2016 .3005

Li, Y., Tong, K. K., Tao, V. Y., Zhang, M. X., \& Wu, A. M. (2020). Testing the Associations among Social Axioms, School Belonging, and Flourishing in University Students: A Two-Year Longitudinal Study. Applied Psychology: Health and Well-Being, 12(3), 749-769. https://doi.org/10.1111/aphw.1220 5

Moule Jr, R. K., Fox, B. H., \& Parry, M. M. (2019). The long shadow of Ferguson: Legitimacy, legal cynicism, and public perceptions of 
police militarization. Crime \& Delinquency, 65(2), 151-182. https://doi.org/10.1177\%2F001112 8718770689

Nair, P, \& Kamalanabhan, T.J. (2010). The Impact of Cynicism on Ethical Intentions of Indian Managers: The moderating role of their level of management. International Journal of Trade, Economics and Finance. 1 (2), 155-159. http://dx.doi.org/10.7763/IJTEF.20 10.V1.28

O'Connor, R., O'Connor, D., O'Connor, S., Smallwood, J., \& Miles, J. (2004). Hopelessness, stress, and perfectionism: The moderating effects of future thinking. Cognition and Emotion, 18(8), 10991120. DOI: 10.1080/02699930441 000067

Putranta, M. P. (2020). The Attitudes toward Codes of Ethics: Do Cynicism and Religiosity Matters?.Media Ekonomi dan Manajemen, 35(1), 128-136. http://dx.doi.org/10.24856/mem.v3 5 i1.1335

Schwartz, S. H., Rubel, T. (2005). Sex differences in value priorities: Cross-cultural and multimethod studies. Journal of Personality and Social Psychology, 89, 1010-1028.

Shek, D. T. L. (2007). Perceived parental control and parent-child relational qualities in Chinese adolescents in Hong Kong. Sex Roles, 53, 635646.

https://doi.org/10.1007/s11199005 7730-7

Stark, J., \& Meschik, M. (2018). Women's everyday mobility: Frightening situations and their impacts on travel behavior. Transportation research part $F$ : traffic psychology and behavior, 54, 311-323. https://doi.org/10.1016/j.trf.2018.0 2.017

Stavrova, O. \& Ehlebracht, D. (2016). Cynical Beliefs about Human Nature and Income: Longitudinal and Cross-Cultural Analyses. Journal of Personality and Social Psychology 110 (1) 116 - 132. https://doi.org/10.1037/pspp00000 50

Tong, K. K., Chen, J. H., Yu, E. W. Y., \& Wu, A. M. (2020). Adherence to COVID-19 precautionary measures: applying the health belief model and generalized social beliefs to a probability community sample. Applied Psychology: Health and Well-Being, 12(4), 1205-1223.

https://doi.org/10.1111/aphw.1223 0

United Nations Department of Economic and Social Affairs. (2020). World Social Report (2020): Inequality in a rapidly changing world. https://www.un.org/development/d esa/dspd/world-social-report/20202.html

Wu, W. C., Chen, S. X., \& Wong, S. S. K. (2019). Predicting gambling propensity and behavior: The role of social axioms and distortive beliefs. Journal of gambling studies, 35(3), 969-986. https://doi.org/10.1007/s10899019-09861-0 